\title{
Protein-Protein Recognition: Crystal Structural Analysis of a Barnase-Barstar Complex at 2.0- $\AA$ Resolution ${ }^{\ddagger}$
}

\author{
Ashley M. Buckle, ${ }^{*}$ Gideon Schreiber, and Alan R. Fersht \\ Cambridge Centre for Protein Engineering, Medical Research Council Centre, Hills Road, Cambridge CB2 2QH, U.K.
}

Received March 1, 1994; Revised Manuscript Received May 9, $1994^{\circ}$

\begin{abstract}
We have solved, refined, and analyzed the $2.0-\AA \AA$ resolution crystal structure of a $1: 1$ complex between the bacterial ribonuclease, barnase, and a Cys $\rightarrow \mathrm{Ala}(40,82)$ double mutant of its intracellular polypeptide inhibitor, barstar. Barstar inhibits barnase by sterically blocking the active site with a helix and adjacent loop segment. Almost half of the 14 hydrogen bonds between barnase and barstar involve two charged residues, and a third involve one charged partner. The electrostatic contribution to the overall binding energy is considerably greater than for other protein-protein interactions. Consequently, the very high rate constant for the barnase-barstar association $\left(10^{8} \mathrm{~s}^{-1} \mathrm{M}^{-1}\right)$ is most likely due to electrostatic steering effects. The barnase active-site residue His 102 is located in a pocket on the surface of barstar, and its hydrogen bonds with Asp39 and Gly31 residues of barstar are directly responsible for the $\mathrm{pH}$ dependence of barnase-barstar binding. There is a high degree of complementarity both of the shape and of the charge of the interacting surfaces, but neither is perfect. The surface complementarity is slightly poorer than in protease-inhibitor complexes but a little better than in antibody-antigen interactions. However, since the burial of solvent in the barnase-barstar interface improves the fit significantly by filling in the majority of gaps, as well as stabilizing unfavorable electrostatic interactions, its role seems to be more important than in other protein-protein complexes. The electrostatic interactions between barnase and barstar are very similar to those between barnase and the tetranucleotide $\mathrm{d}(\mathrm{CGAC})$. In the barnase-barstar complex, the two phosphate-binding sites in the barnase active site are occupied by Asp39 and Gly 43 of barstar. However, barstar has no equivalent for a guanine base of an RNA substrate, resulting in the occupation of the guanine recognition site in the barnase-barstar complex by nine ordered water molecules. Upon barnase-barstar binding, entropy losses resulting from the immobilization of segments of the protein chain and the energetic costs of conformational changes are minimized due to the essentially preformed active site of barnase. However, a certain degree of flexibility within the barnase active site is required to allow for the structural differences between barnase-barstar binding and barnase-RNA binding. A comparison between the bound and the free barstar structure shows that the overall structural response to barnasebinding is significant. This response can be best described as outwardly oriented, rigid-body movements of the four $\alpha$-helices of barstar, resulting in the structure of bound barstar being somewhat expanded.
\end{abstract}

Understanding the nature of the recognition between two protein molecules not only is fundamental to the study of biological processes as diverse as antibody-antigen binding, protease inhibition, muscle contraction, cellular signal transduction, and electron transport by cytochromes but also is a sound foundation for understanding the interactions that are crucial in the protein folding process.

In this paper we describe the $2.0-\AA$ resolution crystal structure of a 1:1 complex between the ribonuclease, barnase, and a double $\mathrm{Cys} \rightarrow \mathrm{Ala}(40,82)$ mutant of its polypeptide inhibitor barstar. Barnase is the 110 -residue extracellular ribonuclease of Bacillus amyloliquefaciens. The same organism produces an 89-residue polypeptide, barstar, which binds tightly to barnase and inhibits its potentially lethal RNase activity inside the cell. The structure of barnase has been solved by X-ray crystallography (Mauguen et al., 1982; A. Cameron and K. Henrick, unpublished results) and NMR spectroscopy (Bycroft et al., 1991). Barnase has proved to be an excellent model for protein stability and folding studies

I Structural coordinates have been deposited in the Brookhaven Protein Data Bank under filename 1BRS.

* Author to whom correspondence should be addressed.

- Abstract published in Advance ACS Abstracts, July 1, 1994.

0006-2960/94/0433-8878\$04.50/0
(Fersht, 1993). Recent structural studies have focused on the nature of the stabilizing interactions within barnase (Buckle et al., 1993; Chen et al., 1993) and on its interactions with small nucleotides (Guillet et al., 1993a; Buckle \& Fersht, 1994). The barnase-barstar interaction has been investigated by kinetic analysis of mutant proteins (Hartley, 1993; Schreiber \& Fersht, 1993a), allowing the binding site on barnase to be mapped and the association and dissociation kinetics to be understood in moderate detail. The NMR solution structure of wild-type barstar has been solved in this laboratory (Lubienski et al., 1994). Crystallographic studies involving wild-type barstar have been thwarted due to the unavoidable presence of a mixture of both oxidized and reduced species, thus necessitating the use of the double Cys $\rightarrow$ Ala mutant. This mutant binds barnase with a dissociation constant of $10^{-13} \mathrm{M}$, compared to $10^{-14} \mathrm{M}$ for wild-type barstar (Hartley, 1993; G. Schreiber, unpublished results).

The structure of the barnase-double Cys $\rightarrow$ Ala barstar mutant complex has recently been independently solved to a resolution of $2.6 \AA$ (Guillet et al., 1993b). The higher resolution of the present structural data allows a more detailed analysis of the individual interactions that constitute the protein-protein recognition. Since the solution structure of barstar has been recently solved in this laboratory (Lubienski 
et al., 1994), the free and bound inhibitor may be compared. Further, we can compare the interaction with that in the barnase-d(CGAC) complex (Buckle \& Fersht, 1994). The analysis focuses on the role in recognition of bound water molecules that are seen at high resolution, the relationship between structure and binding kinetics, and the connection between substrate and inhibitor binding. Elsewhere, the analysis is complementary to the lucid description by Guillet et al. (1993b) of the $2.6-\AA$ structure.

\section{EXPERIMENTAL PROCEDURES}

Barnase and Barstar Production. Expression and purification of barstar and barnase have been described (Serrano et al., 1990; Schreiber \& Fersht, 1993b). For crystallization of the complex, wild-type barnase and the Cys $\rightarrow$ Ala $(40,82)$ double mutant of barstar were used in an equimolar ratio. It was necessary to repurify the barnase-barstar complex on a gel filtration column (Superose 6, Pharmacia) to achieve an exact 1:1 ratio of the two proteins that is crucial for growing diffraction-quality crystals.

Crystallization, Data Collection, and Reduction. Crystals were grown by vapor diffusion using the hanging drop method (McPherson, 1982), from a solution containing 20\% PEG $8000,100 \mathrm{mM}$ Tris- $\mathrm{HCl}, \mathrm{pH} 8.5$, and $100 \mathrm{mM}$ ammonium sulfate. The protein complex $(2.5 \mu \mathrm{L})$ at a concentration of $22 \mathrm{mg} \mathrm{mL}^{-1}$ was mixed with the crystallization solution in a $1: 1$ ratio. Crystals grew after 7 weeks at $23^{\circ} \mathrm{C}$, belonging to space group $C 2$ and having cell dimensions $a=207.25 \AA$, $b=84.71 \AA, c=43.86 \AA$, and $\beta=107.76^{\circ}$. X-ray data were collected from a single crystal (dimensions $1.0 \times 0.5 \times 0.2$ $\mathrm{mm}$ ) on a Mar Research image plate detector, with in-house, monochromatic $\mathrm{Cu} \mathrm{K} \alpha \mathrm{X}$-rays generated by a rotating anode. A full data set could be obtained only if the radiation damage to the crystal was reduced by cooling to $-4^{\circ} \mathrm{C}$. Unless stated otherwise, all data processing, data reduction, electron density syntheses, and structural analyses were carried out using CCP4 software (CCP4, 1979). Indexing and intensity measurements of diffraction data were carried out with the MOSFLM program suite (Leslie, 1990). The final data set is $93 \%$ complete to $2.5 \AA$, and $90 \%$ complete between 2.5 and $2.0 \AA$.

Structure Determination and Refinement. Molecules of barnase were positioned in the unit cell using molecular replacement methods. Based on the estimated percentage solvent content of the unit cell $(\sim 50 \%)$, we expected there to be three barnase-barstar complexes per asymmetric unit. All molecular replacement calculations were performed with the program AMoRe (Navaza, 1987, 1994). For rotation function calculations, a Patterson sphere of radius 4-25 $\AA$ and data in the resolution range 15.0-3.5 $\AA$ gave the highest signal/noise peak ratio in the rotation function map. Barnase wild-type structure (pH 9.0, all atoms in chain C; A. Cameron and K. Henrick, unpublished results) was used as the search model. Cross-rotation function calculations were performed after placing the search model in a $P 1$ cell of dimensions $171 \times 141$ $\times 103 \AA^{3}$ (an optimally sized cell calculated by AMoRe). Two outstanding solutions were found, both having correlation coefficients of $0.12,4 \%$ above the next highest peak. These solutions are consistent with the second highest solution of a self-rotation function calculation ( $29 \%$ of origin peak height, $11 \%$ above the next highest peak) and are related by a 2 -fold rotation axis. Since a higher peak remained in the self-rotation function map ( $34 \%$ of origin peak height), we suspected a third molecule of barnase was to be found. The top 20 crossrotation solutions were each subjected to a translation search, which successfully positioned the top two cross-rotation solutions (resulting in correlation coefficients of 0.16 and 0.30 , respectively). Fortunately, this also identified the eighth highest peak in the cross-rotation calculation as the orientation of the third barnase molecule. This solution, which is related to cross-rotation solution 1 by a 2 -fold rotation axis, had a correlation coefficient of 0.28 and was consistent with the highest peak in the self-rotation function map. Rigid-body refinement of the three molecules, using $\mathrm{AMoRe}$ (Castellano et al., 1992), gave an $R$ factor of $47 \%$ and a correlation coefficient of 0.47 .

Improvement of protein phases was then carried out by 3-fold real-space electron density averaging, using the RAVE package (G. J. Kleywegt and T. A. Jones, unpublished). This requires the definition of a mask covering the noncrystallographic asymmetric unit. It is known that key residues in barnase-barstar association are $\mathrm{His} 102$ and Arg87 in barnase and Asp35 and Asp39 in barstar (Hartley, 1993; Schreiber \& Fersht, 1993a). Using this information, and assuming that both Asp residues on barstar are located in the basic region in the active site of barnase, it was possible to dock an initial model of barstar derived from NMR experiments (Lubienski et al., 1993) into the barnase active site. The mask was then constructed on a $0.7-\AA$ grid by associating a sphere of radius $2.5 \AA$ with each atom. Six cycles of averaging were then carried out with data in the resolution range 7.0-2.0 $\AA$, using $2 F_{0}-F_{\mathrm{c}}$ amplitudes and phases calculated from the averaged map. Although the crude docking of the two proteins resulted in significant error in the constructed mask, the resulting electron density map (having a correlation coefficient of 0.71 and an $R$ factor of $32 \%$ ) was excellent in the barnase region and was clearly interpretable in the barstar region. It was possible to interpret the density for most of the secondary structure for barstar and to correct some regions of barnase, mainly in the active site. Short fragments ( $<5$ residues) of the initial model of uncomplexed wild-type barstar derived from NMR experiments (Lubienski et al., 1994) were used to build in most segments of the barstar chain. All model building was carried out with the program $\mathrm{O}$ (Jones et al., 1991) running on an SGI Indigo ${ }^{2}$ Extreme workstation. A new map and mask were calculated from this partial structure, and a further six cycles of averaging were carried out. Map interpretation and averaging were repeated once more until all residues of barstar had been built, with the exception of the region 57-75. The main chain for the helical and sheet regions of barstar was reconstructed from a database of refined structures within $O$. The whole asymmetric unit was generated using the latest noncrystallographic symmetry (NCS) operators. The resulting model, $\mathrm{M} 3$, had an $R$ factor of $47.1 \%$ for all diffraction data in the resolution range 7.0-2.0 $\AA$.

Initial structure refinement consisted of macrocycles of positional refinement with XPLOR (Brunger, 1992), updating the NCS operators and mask, six cycles of real-space averaging, and rebuilding the model in averaged maps. Each atom was given a constant temperature factor of $25 \AA^{2}$, calculated from a Wilson (1949) plot within the program TRUNCATE. Up to model M5, only one complex was rebuilt and the other two complexes generated from NCS operators. At this stage, averaging did not further improve the map so it was terminated (the final averaged map had a correlation coefficient of 0.91 and an $R$ factor of $25 \%$ ). Subsequent refinement was performed with the program PROLSQ. Each complex in the asymmetric unit was inspected separately, and rebuilding was greatly aided by the use of a real-space $R$ factor calculation in the program $O$. The fit between the protein atoms and the $2 F_{\mathrm{o}}-F_{\mathrm{c}}$ electron density was calculated and used to color- 


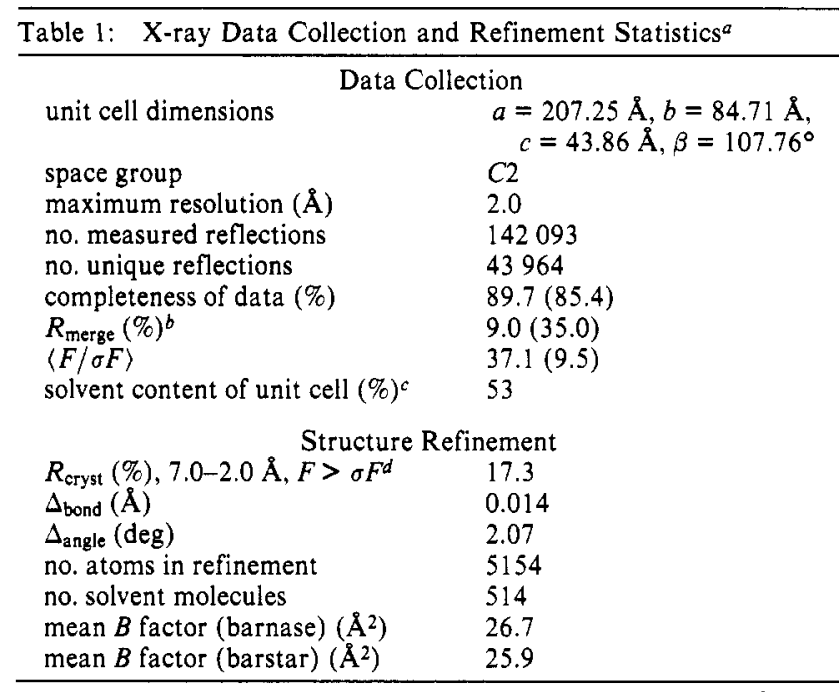

${ }^{a}$ Values given in parentheses are for the highest resolution shell. ${ }^{b} R_{\text {merge }}$ gives the agreement between intensities of repeated measurements of the same reflections and can be defined as $\sum\left(I_{h, i}-\left\langle I_{h}\right\rangle\right) / \sum I_{h, i}$, where $I_{h, i}$ are individual values and $\left\langle I_{h}\right\rangle$ is the mean value of the intensity of reflection $h{ }^{c}$ Calculated by the CCP4 program TRUNCATE. $d$ The crystallographic $R$ factor, $R_{\text {cryst }}$, is defined as $\Sigma\left|F_{0}-F_{\mathrm{c}}\right| / \Sigma F_{0}$.

code the protein chain as a means of identifying poorly fitting regions. Data collection and structure refinement are summarized in Table 1.

Solvent molecules were added only if they had acceptable hydrogen-bonding geometry contacts of $2.5-3.5 \AA$ with protein atoms or with existing solvent and were in good $2 F_{0}-F_{\mathrm{c}}$ and $F_{\mathrm{o}}-F_{\mathrm{c}}$ electron density. Peaks above $3.0 \sigma$ in the $F_{\mathrm{o}}-F_{\mathrm{c}}$ map were found using the program PEAKMAX and examined for contacts with protein or solvent atoms with the program WATPEAK. Occupancy of solvent molecules was set at unity and not refined. Barnase chains are labeled $\mathrm{A}, \mathrm{B}$, and $\mathrm{C}$, and the corresponding barstar chains are labeled $\mathrm{D}, \mathrm{E}$, and $\mathrm{F}$. The three complexes are, therefore, $\mathrm{AD}, \mathrm{BE}$, and $\mathrm{CF}$.

Structural Comparisons, Surface Complementarity Calculations, and Other Software Used. Unless stated otherwise, all analysis was carried out with the AD barnase-barstar complex. Structural comparisons involving wild-type barnase were performed using chain $C$ of the barnase wild-type crystal structure solved at $\mathrm{pH} 9.0$ (K. Henrick and A. Cameron, unpublished results). Structural comparisons with uncomplexed wild-type barstar used the restrained, energyminimized, average NMR structure (Lubienski et al., 1994). Similarly, analysis involving the structure of the barnased(CGAC) complex (Buckle \& Fersht, 1994) used barnase chain $\mathrm{L}$ and nucleotide chain $\mathrm{A}$. Least-squares superpositions of structures were carried out within the program O (Jones et al., 1991). Potential hydrogen-bonding interactions were analyzed using the CCP4 program CONTACT. Surface complementarity was calculated by the program SHAPE (M. C. Lawrence and P. M. Colman, Biomolecular Research Institute, Parkville, Australia). This program calculates the shape correlation statistic $\left(S_{\mathrm{c}}\right)$ of interacting molecular surfaces (Lawrence \& Colman, 1993). Molecular surfaces were generated using the method of Connolly (1983), using a probe of $1.4 \AA$ and a surface dot density of 15 dots $\AA^{-2}$. Molecular volumes were calculated by GRASP (Nicholls, 1992). Accessible surface area calculations were performed with the AREA set of programs (P. Brick, Imperial College, London). Solvent molecules were sorted according to the protein chain to which they are associated with, using the CCP4 program WATERSORT.

\section{RESULTS}

Quality of the Final Model. The final model, M10, consisting of 4640 protein atoms and 514 solvent molecules, has a crystallographic $R$ factor of $17.2 \%$ for all data in the resolution range 7.0-2.0 $\AA$. The model is complete with the following exceptions: barnase chains $\mathrm{A}$ and $\mathrm{C}$ are missing residues 1 and 2 from the $\mathrm{N}$-terminus. This $\mathrm{N}$-terminal disorder is a common feature in all barnase structures solved to date. These residues are present, however, in the barnase B chain of the barnase-barstar complex as a result of stabilizing crystal packing interactions. There is no density for the $\mathrm{N}$-terminal lysine residue of barstar chain $\mathrm{E}$. It was impossible to build in residues 64 and 65 of barstar chains D and $E$ because of relatively high disorder in this region of barstar. Overall, the model has excellent stereochemistry: deviation from bond length and bond angle ideality is $0.014 \AA$ and $2.1^{\circ}$, respectively. On the basis of a stereochemical analysis with the program PROCHECK (Morris et al., 1992), $88 \%$ of residues have backbone $\phi, \psi$ angles within the most favored regions of the Ramachandran plot. No residues have disallowed backbone $\phi, \psi$ angles. The main-chain and sidechain stereochemistry of the model is better than that derived from the $1182.0-\AA$ resolution protein structures used in the PROCHECK analysis. Ser14 of barstar chain D has two clearly defined side-chain conformations $\left(\chi_{1}=-51^{\circ}\right.$ and $150^{\circ}$, respectively). Both were given an occupancy of 0.5 and included in the refinement. The electron density around the side chain of Val45 in all three barstar chains suggests 2-fold disorder, but this was unstable when incorporated into the refinement. No residues of barnase were modeled as being discretely disordered.

Description of the Asymmetric Unit. The three complexes in the asymmetric unit which will subsequently be referred to as $\mathrm{AD}, \mathrm{BE}$, and $\mathrm{CF}$ are shown in Figure 1. There are notable differences in atomic temperature factors between the three complexes. The most significant difference is the very high overall temperature factor for barnase chain $\mathrm{C}$ compared to chains $A$ and $B$ (Table 3 and Figure 3 ). The overall fit between the model and electron density is also very poor for this chain (Figure 2), particularly in the polypeptide segment of residues 29-50, which corresponds to the second and third $\alpha$-helices and connecting loop segments. This is most likely due to a lack of stabilizing crystal packing around this molecule, which is also less solvated than the other molecules in the asymmetric unit. The differences in mobility of corresponding residues in each of the three complexes is described in more detail below. As there are no significant structural differences between the three barnase molecules, the disorder of barnase molecule $\mathrm{C}$ may well be an explanation for the difficulty in finding the orientation of this molecule by molecular replacement (a least-squares fit of the $\mathrm{C} \alpha$ atoms of chains B and C with chain $A$ gives $C \alpha \mathrm{rms}^{1}$ deviations of 0.31 and $0.26 \AA$, respectively).

Each barstar molecule is oriented in the crystal such that the last strand of the three-stranded parallel $\beta$-sheet lies close to the crystallographic 2-fold and hydrogen-bonds to its symmetry equivalent in an antiparallel $\beta$-sheet fashion.

Barnase-Barstar Interactions and the Nature of the Interface. The mode of inhibition of barnase by barstar is very simple - the active site of barnase is sterically blocked

\footnotetext{
${ }^{1}$ Abbreviations: Rms, root-mean-square; ASA, accessible surface area.
} 


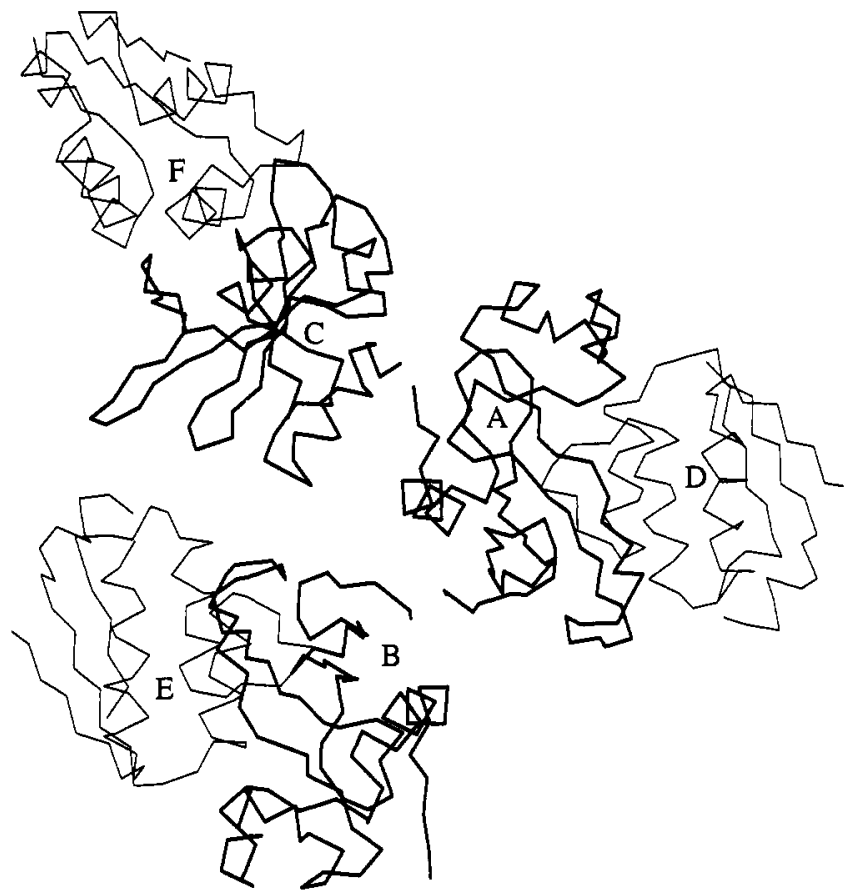

FIGURE 1: $\mathrm{C} \alpha$ trace of the three barnase-barstar complexes in the asymmetric unit, viewed approximately down the 2-fold noncrystallographic axis between complexes $\mathrm{AD}$ and $\mathrm{BE}$. Rotating by $\sim 35^{\circ}$ around the horizontal axis in the plane of paper results in a view down the crystallographic $b$-axis. The other noncrystallographic 2 -fold symmetry between complexes AD and CF is not apparent from this representation but is perpendicular to the crystallographic $b$-axis $\left(\sim 55^{\circ}\right.$ rotation around horizontal axis in plane of paper). All chains are labeled. Barnase chains are drawn in thick lines, barstar chains in thin lines [drawn with MolScript (Kraulis, 1991)].

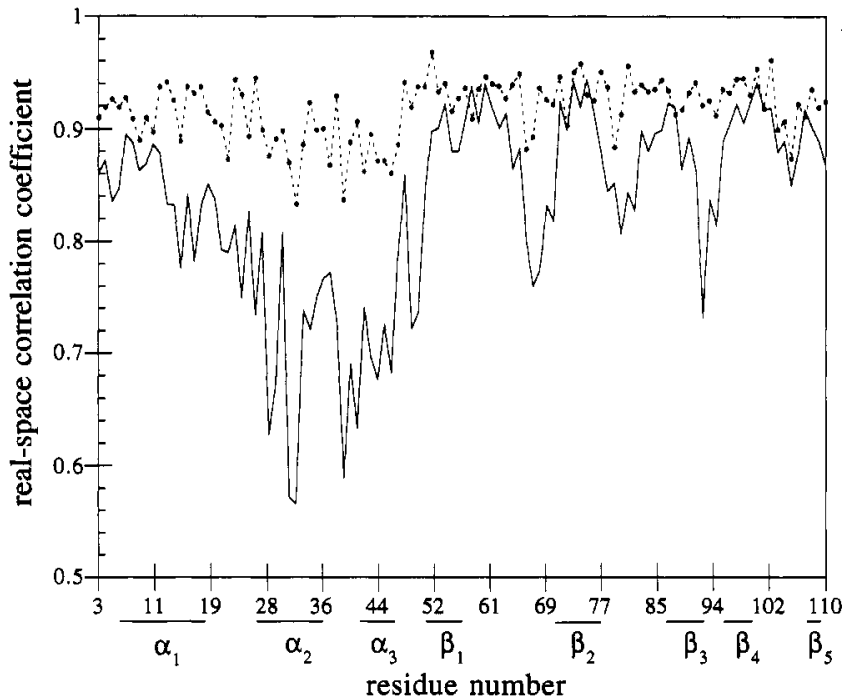

FIGURE 2: Fit between electron density and the model as indicated by the real-space correlation coefficient calculated within $O$ (Jones et al., 1991). The real-space fit for barnase chain A (broken lines) is representative of all protein chains in the asymmetric unit, except for barnase chain $C$ (continuous line). The regions of secondary structure of barnase are indicated below the $x$-axis.

by barstar $\alpha$-helix $_{2}$ and the loop connecting this to $\alpha$-helix (Figure 4; Guillet et al., 1993b). Upon formation of the complex, $1590 \AA^{2}$ of solvent-accessible surface area is buried at the interface, $803 \AA^{2}$ by barnase, and $787 \AA^{2}$ by barstar. Similar figures are calculated for the $2.6-\AA$ barnase-barstar complex (Guillet et al., 1993b). The catalytically important residues of barnase, His102, Arg83, Arg87, and Lys27, all interact with barstar through salt bridges and hydrogen bonds. In total, there are 14 hydrogen bonds between barnase and
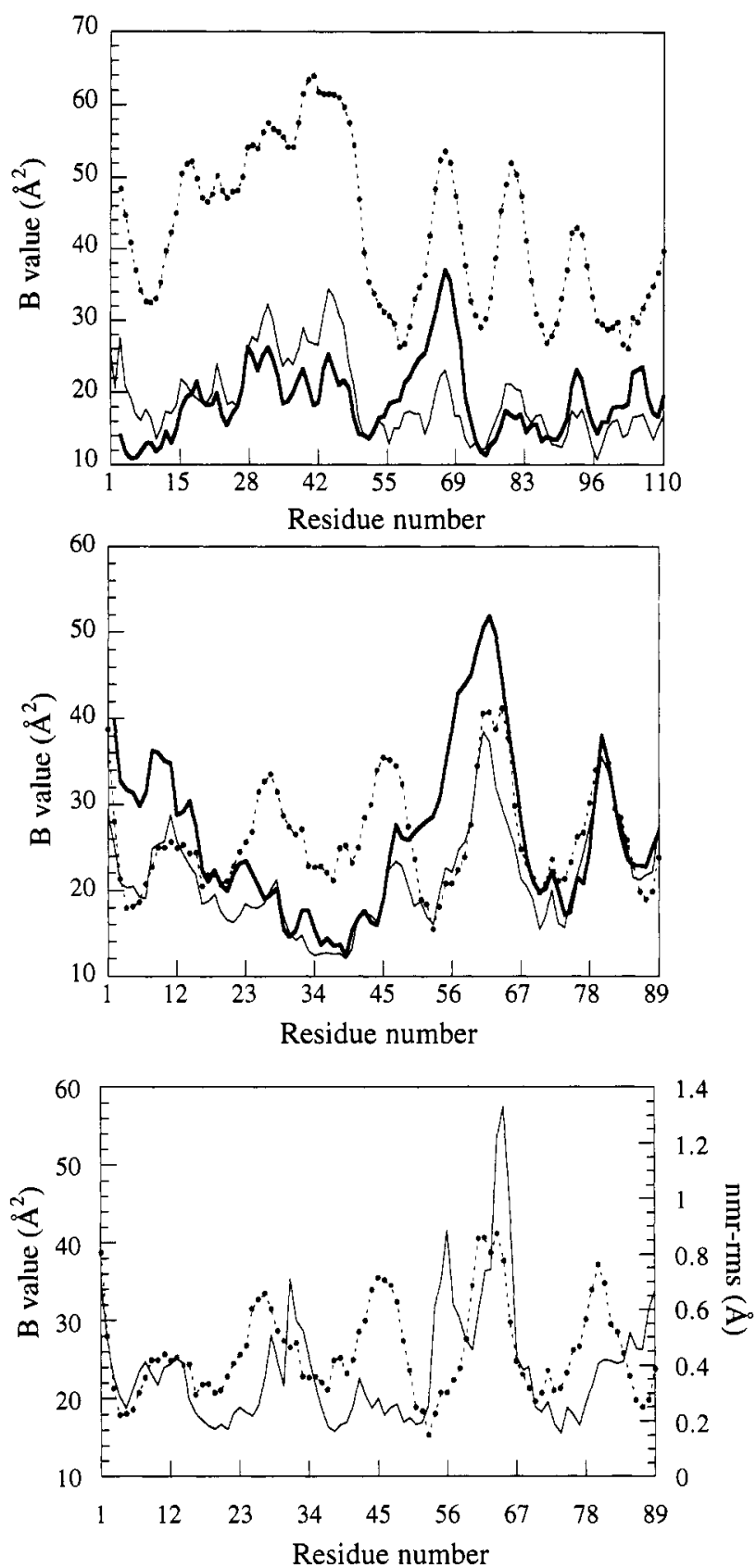

FIGURE 3: Main-chain atomic-temperature factors for residues in the barnase-barstar complex. (Top) Barnase ABC chains; (middle) barstar DEF chains; (bottom) barstar F chain plotted alongside mainchain rms values for energy-minimized, average barstar wild-type NMR structure (Lubienski et al., 1994). In all plots, bold lines represent chains $A$ and $D$, thin lines represent chains $B$ and $E$, and broken lines represent chains $C$ and $F$. The rms values for the NMR structure are represented by a continuous line.

barstar (Table 2). The interactions at the interface are predominantly electrostatic in nature, as illustrated in Figure 5 (top). There are six hydrogen bonds involving both charged donor and acceptor groups and four hydrogen bonds involving one charged partner. The remaining four hydrogen bonds are between uncharged residues. On the whole, the interacting surfaces have a high degree of charge complementarity in that the negative electrostatic potential resulting from the location of Asp35 and Asp39 on the exposed face of barstar $\alpha$-helix ${ }_{2}$ interacts favorably with the electropositive base of the barnase active site, formed by the clustering of residues Lys27, Arg83, and Arg87.

The degree of complementarity between the interacting protein surfaces was assessed by calculating the shape 


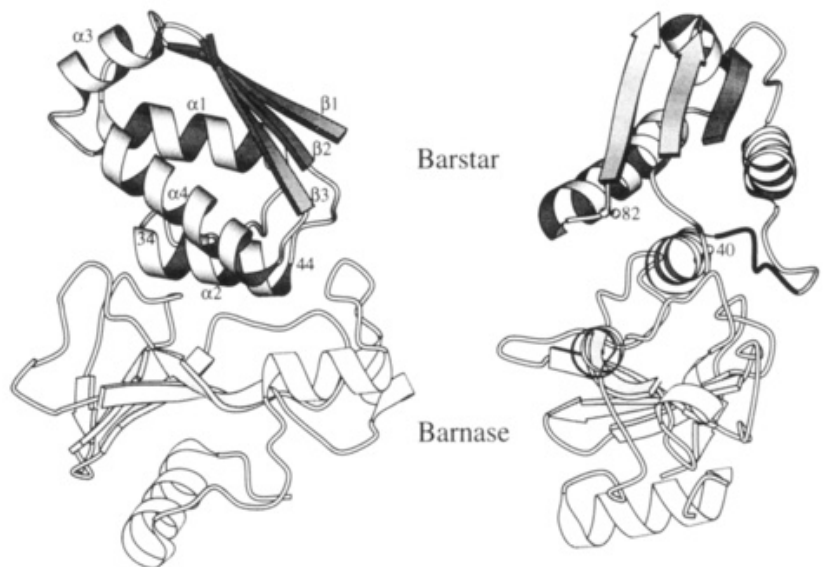

Figure 4: Orthogonal views of the barnase-barstar complex. The barstar structure is heavily shaded and the barnase structure lightly shaded. The secondary structure elements of barstar are labeled. The $\mathrm{N}$ - and C-caps of barstar $\alpha$-helix ${ }_{2}$ are also labeled. The barstar loop (29-33) that is involved in barnase binding is drawn in black. The side chains of the mutated barstar residues are shown as ball-andstick models and are labeled [drawn with MolScript (Kraulis, 1991)].

Table 2: Hydrogen-Bonding Interactions between Barnase and Barstar $^{a}$

\begin{tabular}{|c|c|c|c|}
\hline $\begin{array}{l}\text { barstar } \\
\text { residue }\end{array}$ & $\begin{array}{l}\text { barnase } \\
\text { residue }\end{array}$ & D...A $(\AA)$ & D-H...A (deg) \\
\hline \multirow{2}{*}{ OH Tyr 29} & O Asn 84 & 3.1 & 99 \\
\hline & O Arg83 & 2.7 & 108 \\
\hline N Gly31 & ND1 His102 & 3.0 & 162 \\
\hline ND2 Asn 33 & O His 102 & 3.2 & 145 \\
\hline N Leu34 & OE2 Glu60 & 2.8 & 131 \\
\hline OD1 Asp35 & N Arg59 & 2.9 & 152 \\
\hline \multirow{2}{*}{ OD1 Asp39 } & NH2 Arg83 & 2.5 & 154 \\
\hline & NH1 Arg83 & 2.9 & 131 \\
\hline \multirow[t]{2}{*}{ OD2 Asp39 } & NH2 Arg87 & 2.9 & 168 \\
\hline & NE2 His102 & 2.8 & 171 \\
\hline OG1 Thr42 & NZ Lys27 & 3.0 & \\
\hline O Gly43 & NH1 Arg83 & 3.1 & 158 \\
\hline \multirow{2}{*}{ OE1 Glu76 } & NH2 Arg59 & 3.0 & 147 \\
\hline & NH1 Arg59 & 3.0 & 147 \\
\hline
\end{tabular}

${ }^{a}$ All contacts shorter than $3.25 \AA$ with $\mathrm{D}-\mathrm{H} \cdots \mathrm{*}$ A angle greater than $120^{\circ}$ and $\mathrm{X}-\mathrm{O} \cdots \mathrm{H}$ angle greater than $90^{\circ}$ are shown (D, hydrogen bond donor; A, hydrogen bond acceptor). Bond angles are not given for hydrogen bonds involving lysine $\mathrm{NZ}$ atoms since the hydrogen position is ambiguous. Values were calculated with the CCP4 program CONTACT.

correlation statistic, $S_{\mathrm{c}}$ (Lawrence \& Colman, 1993). For two perfectly complementary surfaces, $S_{\mathrm{c}}=1.0$. Conversely, for surfaces with no complementarity, $S_{\mathrm{c}} \approx 0$. For the barnasebarstar complex, $S_{\mathrm{c}}=0.70$. Lawrence and Colman (1993) found that for protein oligomeric and protease-inhibitor interfaces, $S_{\mathrm{c}}$ ranges from 0.70 to 0.76 , whereas for antibodyantigen interfaces, the complementarity is poorer, with $S_{\mathrm{c}}$ in the region of $0.64-0.68$.

The barnase-barstar interface can be best described by dividing it up into two areas, those of the interacting surfaces separated by $\alpha$-helix ${ }_{2}$ of barstar (Figure 6). On one side of barstar $\alpha$-helix ${ }_{2}$, there are extensive interactions between Asp39 of barstar and the basic residues in the barnase active site (Figure 6, top). The complementarity between the interacting protein surfaces is very good (Figure 5), with few gaps at the interface.

The nature of the interactions and environment on the opposite side of $\alpha$-helix ${ }_{2}$, however, is very much a contrast (Figure 6, bottom). The surface complementarity here is rather poor, particularly in the vicinity of the guanine binding site. The gaps in between surfaces are seen to be almost completely filled with ordered water molecules (Figure 7). The large cavity containing nine water molecules, also described by Guillet et al. (1993b), is formed partly by the ordering of the barnase Arg59 side chain. This residue is very mobile in the free barnase structure but is ordered upon substrate binding and stacks directly onto the guanine base (Buckle \& Fersht, 1994). In the barnase-barstar complex, it lies less directly above the guanine site and points more outward, where it can make two hydrogen bonds with the side chain of barstar Glu76. Along with the side chain of barnase His102 and barstar Asp35, Arg59 buries the largest accessible surface area upon complexation $\left(110,122\right.$, and $162 \AA^{2}$, respectively). These values can be somewhat misleading, however, since the packing around Arg59 of barstar and Asp35 is relatively loose, both residues lining a cavity. His 102 of barnase fits into a deep invagination on the surface of barstar but does not penetrate enough to fill it completely.

The side chain of Asn 33 is positioned at the N-terminus of barstar $\alpha$-helix ${ }_{2}$ so that it may hydrogen-bond with barnase His 102 carbonyl oxygen and with the exposed $>\mathrm{NH}$ group of Ala36 in barstar $\alpha$-helix 2 (the N-cap; Richardson \& Richardson, 1988). Although Asn is statistically one of the most favorable residues at the $\mathrm{N}$-cap of $\alpha$-helices (Richardson \& Richardson, 1988), it was found that this residue was energetically unfavorable compared with $\mathrm{Thr}$, at the $\mathrm{N}$-caps of both helices in barnase (Serrano \& Fersht, 1989). Serrano and Fersht suggest that the N-capping potential of Asn is increased when its $\mathrm{NH}_{2}$ group can make other hydrogen bonds with protein. The interactions of the Asn $33 \mathrm{~N}$-cap in the barnase-barstar complex support this argument and reinforce the view that, generally, the choice of residue at the $\mathrm{N}$-cap will greatly depend on the structural context. Barstar $\alpha$-helix has an additional N-cap interaction with Glu60 of barnase, which hydrogen-bonds to Leu34 $>\mathrm{NH}$. The favorable charged interaction between the helix macrodipole and Glu60 could contribute 1-2 kcal mol-1 to barnase-barstar binding (Nicholson et al., 1988; Sali et al., 1988; Serrano \& Fersht, 1989).

There Are Structural Parallels between Barnase-Barstar Binding and Barnase-Nucleotide Binding. The interactions between barnase and barstar have been compared with those between barnase and 3'-GMP (Guillet et al., 1993a). We extend this analysis to include the barnase-d(CGAC) interaction (Buckle \& Fersht, 1994). There are binding sites for two phosphate groups of an RNA substrate (Baudet \& Janin, 1991; Buckle \& Fersht, 1994). The site of phosphodiester cleavage (the $p_{1}$ phosphate site) is occupied by Asp39 in the barnase-barstar complex. The Asp39-barnase electrostatic interactions are extremely similar to the barnase- $\mathrm{p}_{1}$ interactions (Guillet et al., 1993b). The second phosphate binding site (the $\mathrm{p}_{2}$ phosphate subsite) is occupied partly by the mainchain carbonyl of barstar residue Gly43 and a buried water molecule (Wat155). The stacking interaction between barnase His 102 side chain and the aromatic ring of barstar Tyr29 is similar to the His102-adenine interaction in the barnased(CGAC) complex (Buckle \& Fersht, 1994), although the latter is a face-to-face interaction and the former is a faceto-edge arrangement. The stable planar stacking arrangement between a guanine base and the Arg59 guanidinium group that is observed in barnase-nucleotide complexes (Guillet et al., 1993a; Buckle \& Fersht, 1994) resembles the Arg59barstar Trp38 interaction. The latter arrangement is not as planar or as close but could be explained by a hypothesis of Flocco and Mowbray (1994), who found a statistical preference 

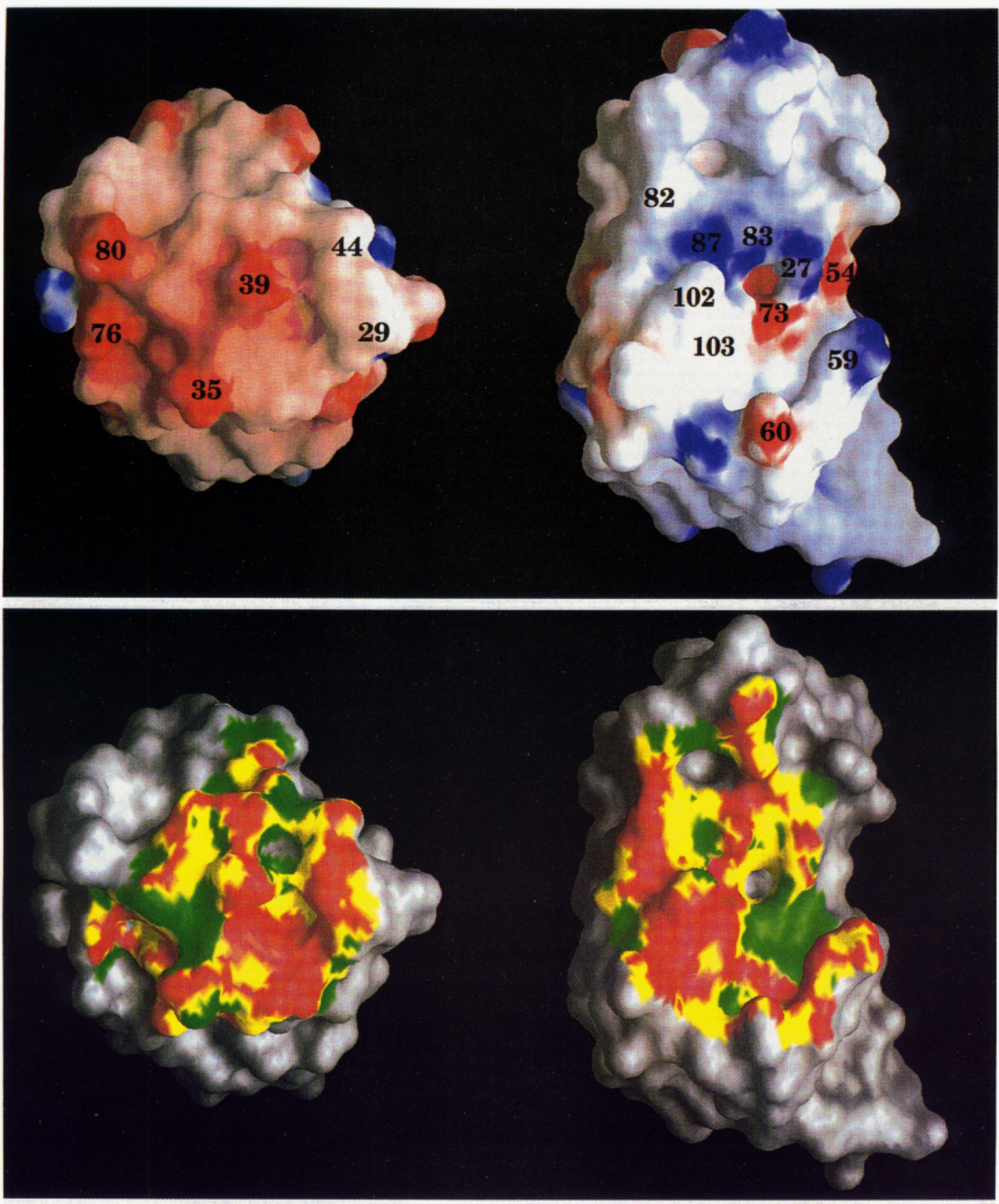

\section{Barstar}

Barnase

FIGURE 5: Molecular surfaces of barnase and barstar. Associated complexes are formed by rotating each molecule by $90^{\circ}$ around the vertical axis in the plane of the paper (clockwise for the left molecules, anticlockwise for the right molecules). (A, top) Surface color coded according to electrostatic potential [calculated by the Poisson-Boltzmann solver within GRASP and displayed within GRASP (Nicholls, 1992)]. Lys and Arg residues were assigned a single positive charge, and Asp and Glu residues were assigned a single negative charge. The side chain of His 102 was treated as neutral, in accordance with its measured $\mathrm{p} K_{\mathrm{a}}$ of 6.3 (Sali et al., 1988). All other residues were considered neutral. The calculation was done assuming a uniform dielectric constant of 80 for the solvent and 2 for the protein interior. The ionic strength was set to zero. The color of the surface represents the electrostatic potential at the protein surface, going from blue (potential of $+4.7 k T / e)$ to red (potential of $-2.4 k T / e$ ). $T$ is temperature, $e$ is the charge of the electron, and $k$ is the Boltzmann constant. The probe radius used was 1.4 $\AA$. This representation clearly shows the electrostatic interactions between barnase and barstar at the interface. (B, bottom) Surfaces color coded according to shape correlation $\left(S_{\mathrm{c}}\right)$. Red, $S_{\mathrm{c}}>0.76$; yellow, $0.76>S_{\mathrm{c}}$; green, $0.3>S_{\mathrm{c}}>-0.3$; gray, noninteracting portions of the molecular surface. $S_{\mathrm{c}}$ was calculated by the program SHAPE (M. C. Lawrence and P. M. Colman, Biomolecular Research Institute, Parkville, Australia) and is a measure of the degree of complementarity of the molecular surfaces at the interface between two molecules (see text). Red areas represent almost complete meshing of the two surfaces, whereas green areas have a much poorer fit, with significant voids between the surfaces. In the representations of barstar, the binding helix $\left(\alpha\right.$-helix $\left.x_{2}\right)$ is running approximately vertically. Interface residues are labeled.

for Arg-aromatic stacking in proteins and argue that this might serve to orient and stabilize the guanidinium group without interfering with its hydrogen-bonding capacity. In this manner, it is possible that the aromatic ring of barstar Trp38 facilitates the positioning of Arg59 for optimal hydrogen-bonding with barstar Glu76. 

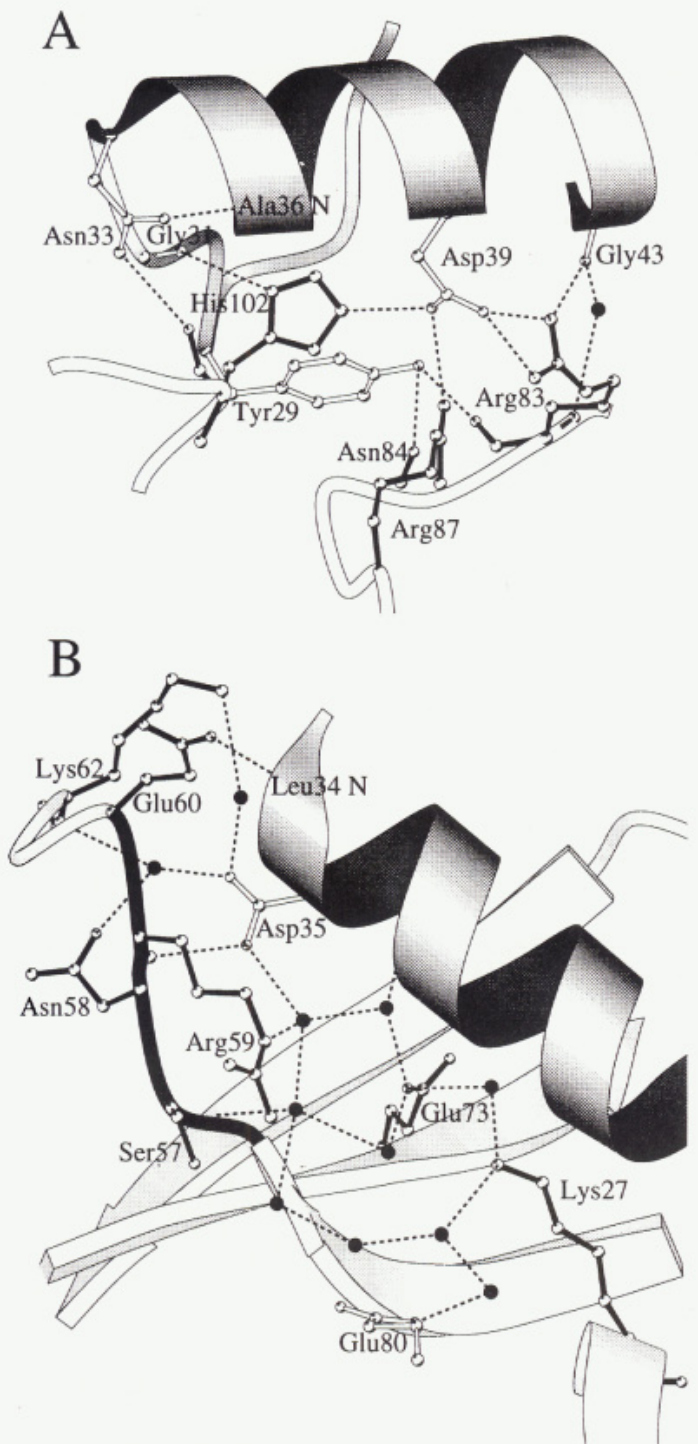

FIGURE 6: Two representations of the interactions at the barnasebarstar interface. Barstar secondary structure is heavily shaded, barnase lightly shaded. Residues are drawn as ball-and-stick models, filled bonds for barnase, empty bonds for barstar. Water molecules are represented as black spheres. Each diagram shows contrasting views of the interface at opposite sides of barstar $\alpha$-helix 2 . (A, top) Tightly packed core of the interface, showing the interaction between Asp39 of barstar with the basic residues in the barnase active site. (B, bottom) Opposite face of barstar $\alpha$-helix ${ }_{2}$, showing the barnase guanine binding site that is partly occupied by ordered solvent. The guanine recognition loop of barnase has been colored black. Hydrogen bonds are represented by broken lines [drawn with MolScript (Kraulis, 1991)].

Solvent Plays a Crucial Role in the Barnase-Barstar Interaction. There are 35 water molecules within $4.5 \AA$ of both protein molecules. These can be grouped and analyzed according to how buried they are in the interface (Figure 7). Six of the seven water molecules that are completely buried in the interface fill in the region of poor surface complementarity in the guanine binding site. Five of these mediate hydrogen bonds between barnase and barstar (Table 4). All of the nine water molecules that mediate barnase-barstar hydrogen bonds have relatively low $B$ values and are generally as ordered as protein residues at the interface (Tables 3 and 4). All but one are also present in the BE and CF complexes (equivalent to $\pm 0.50 \AA$ ). Each of the second group of five water molecules has a solvent accessibility of less than $10 \AA^{2}$ and is more distributed over the interface. Three of these mediate barnase-barstar hydrogen bonds. The remaining

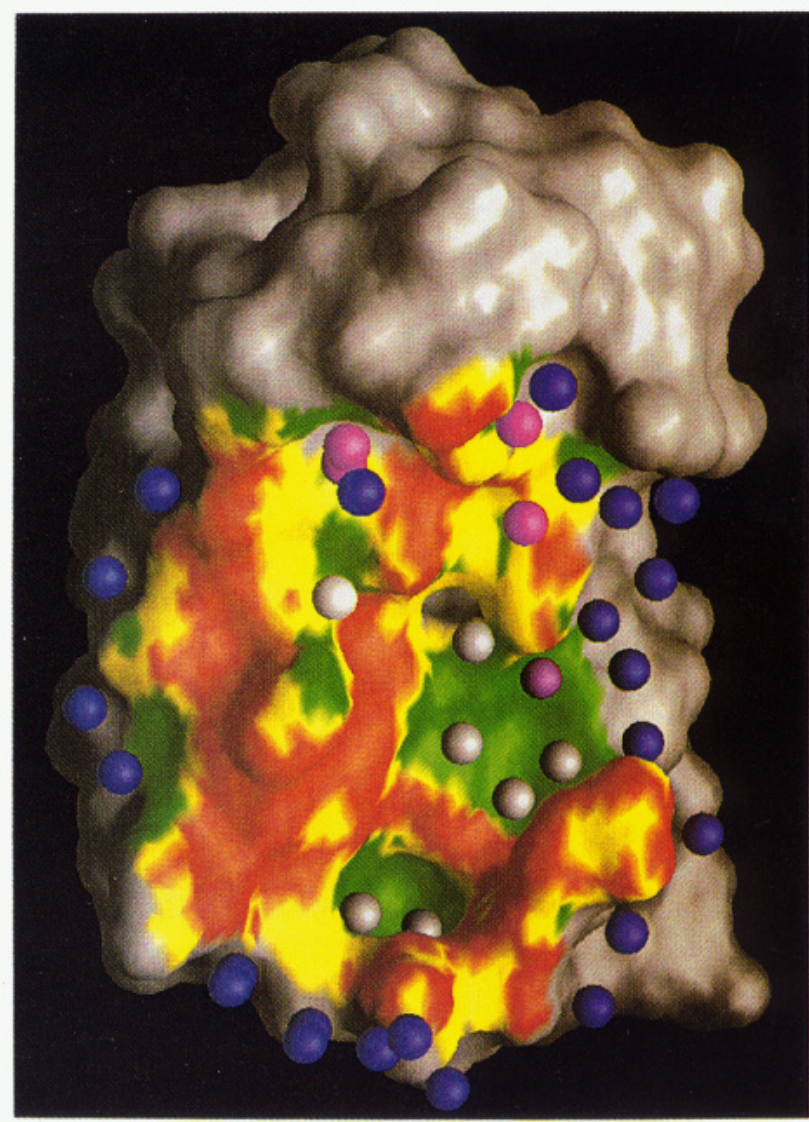

FIGURE 7: Molecular surface of barnase color coded by shape correlation as in Figure 5, viewed directly at the active site and showing interfacial water molecules. The water molecules are represented as spheres of radii half that of $\mathrm{O}$ atoms and are color coded according their solvent-accessible surface area (ASA, in $\AA^{2}$ ). Silver, ASA = 0 ; magenta, $0<$ ASA $<10$; blue, ASA $>10$. It is clear from this representation that the solvent fills in regions of poor complementarity of the surfaces and creates a "rim" around the edge of the interface. The surface was calculated and drawn with GRASP (Nicholls, 1992).

Table 3: Atomic Temperature Factors $(B)$ of Individual Chains in the Barnase-Barstar Complex

\begin{tabular}{lcccr}
\hline & $\begin{array}{c}\text { mean } \\
\text { main-chain } \\
\text { chain }\end{array}$ & $\begin{array}{c}\text { mean } \\
\text { side-chain } \\
\left.\AA^{2}\right)\end{array}$ & $\begin{array}{c}\text { mean } B \text { of } \\
\text { interface } \\
\text { residues } \\
\left(\AA^{2}\right)\end{array}$ & $\begin{array}{r}\left(\AA^{2}\right)^{a} \\
\text { no. solvent } \\
\text { molecules }^{b}\end{array}$ \\
\hline barnase A & 19.0 & 20.0 & 18.7 & $136(37.6)$ \\
B & 18.9 & 19.7 & 18.2 & $120(36.8)$ \\
C & 42.5 & 41.3 & 36.0 & $66(44.9)$ \\
barstar D & 21.2 & 24.4 & 15.5 & $80(41.2)$ \\
E & 26.1 & 28.3 & 16.5 & $70(42.5)$ \\
F & 26.1 & 29.2 & 26.9 & $43(40.7)$ \\
\hline
\end{tabular}

${ }^{a}$ Residues in the interface that have protein-protein interactions within $3.6 \AA$. These are as follows: barnase $-27,37-38,56,59-60,83-85,87$, 102-104; barstar-29, 31, 33-36, 38-39, 42-44, 76. The mean $B$ value of all atoms in the residues is given. ${ }^{b}$ Number of solvent molecules associated with each chain, calculated using the CCP4 program WATERSORT. Mean $B$ values are given in brackets.

group of water molecules has solvent accessibilities ranging from 11 to $56 \AA^{2}$. This set forms the "rim" of the interface and is less well ordered. Although only one "rim" water mediates a barnase-barstar hydrogen bond directly, 10 are involved in hydrogen bonds of the type barnase-water-waterbarstar.

Of the 12 water molecules that have accessible surface areas of less than $10 \AA^{2}$, five are seen in the free barnase structure. None of the solvent at the interface rim is conserved in the free barnase structure. The two water molecules that are 
Table 4: Solvent-Mediated Hydrogen Bonding between Barnase and Barstar $^{a}$

\begin{tabular}{|c|c|c|c|c|}
\hline solvent & residues $^{b}$ & D...A $(\AA)$ & $\begin{array}{c}\text { solvent } \\
\operatorname{ASA}\left(\AA^{2}\right)^{c}\end{array}$ & $\begin{array}{c}\text { solvent } B \\
\text { values }\left(\AA^{2}\right)^{d}\end{array}$ \\
\hline Wat14 & $\begin{array}{l}\text { O Asp35 } \\
\text { OE2 Glu73 }\end{array}$ & $\begin{array}{l}2.9 \\
3.2\end{array}$ & 0.0 & $11.5,11.3,27.4$ \\
\hline Wat22 & $\begin{array}{l}\text { OD2 Asp35 } \\
\text { N Lys62 } \\
\text { OD1 Asn58 }\end{array}$ & $\begin{array}{l}2.8 \\
3.2 \\
2.8\end{array}$ & 0.0 & $15.2,19.5,24.8$ \\
\hline Wat29 & $\begin{array}{l}\text { OD1 Asp35 } \\
\text { NE Arg59 }\end{array}$ & $\begin{array}{l}2.8 \\
2.9\end{array}$ & 0.0 & $16.0,18.7,28.4$ \\
\hline Wat33 & $\begin{array}{l}\text { OD1 Asp39 } \\
\text { NZ Lys27 } \\
\text { OE2 Glu73 }\end{array}$ & $\begin{array}{l}2.6 \\
2.5 \\
3.0\end{array}$ & 0.0 & $20.3,17.9,32.5$ \\
\hline Wat36 & $\begin{array}{l}\text { O Val45 } \\
\text { OG Ser38 } \\
\text { N Ser38 }\end{array}$ & $\begin{array}{l}2.6 \\
2.9 \\
2.8\end{array}$ & 9.0 & $19.8,18.8$ \\
\hline Wat48 & $\begin{array}{l}\text { NE1 Trp38 } \\
\text { O Ile55 } \\
\text { OE2 Glu73 }\end{array}$ & $\begin{array}{l}3.2 \\
2.7 \\
2.7\end{array}$ & 3.0 & $16.2,20.1,25.4$ \\
\hline Wat93 & $\begin{array}{l}\text { N Tyr47 } \\
\text { OG Ser38 }\end{array}$ & $\begin{array}{l}3.0 \\
2.8\end{array}$ & 17.0 & $24.0,27.4,54.4$ \\
\hline Wat128 & $\begin{array}{l}\text { OD2 Asp35 } \\
\text { NZ Lys62 } \\
\text { O Tyr103 }\end{array}$ & $\begin{array}{l}2.7 \\
3.1 \\
2.7\end{array}$ & 0.0 & $22.7,21.3,40.9$ \\
\hline Wat155 & $\begin{array}{l}\text { O Gly43 } \\
\text { N Arg83 }\end{array}$ & $\begin{array}{l}3.0 \\
3.2\end{array}$ & 1.0 & $25.2,15.6,54.3$ \\
\hline
\end{tabular}

${ }^{a}$ All contacts shorter than $3.25 \AA$ with a D-H...A angle greater than $120^{\circ}$ and an $\mathrm{X}-\mathrm{O} \cdots \mathrm{H}$ angle greater than $90^{\circ}$ are shown (D, hydrogen bond donor; A, hydrogen bond acceptor). Values were calculated with the CCP4 program CONTACT. ${ }^{b}$ Barstar residues are in boldface. ${ }^{c}$ Accessible surface area. ${ }^{d} \boldsymbol{B}$ values are given for the equivalent solvent in each complex, in the order $\mathrm{AD}, \mathrm{BE}, \mathrm{CF}$.

present in the active site of the free structure but absent in the complex have been substituted by oxygen atoms in barstar residues Gly43 and Asp39.

When the buried interfacial solvent (12 molecules with accessible surface areas $<10 \AA^{2}$ ) is included in the shape correlation calculation, $S_{\mathrm{c}}$ increases dramatically from 0.70 to 0.82 . This improvement is significantly larger than those generally found for protease-inhibitor complexes (Lawrence \& Colman, 1993), emphasizing the important role played by solvent in the barnase-barstar interaction.

Barnase-Barstar Binding Produces Only Localized Changes in Barnase Structure. Overall, the structure of barnase in the barnase-barstar complex is almost identical to that found in the free structure. The rms deviation between $\mathrm{C} \alpha$ positions of free and complexed barnase structures, after a least-squares fit of all $\mathrm{C} \alpha$ atoms, is $0.45 \AA$. Most structural differences are similar to those found in the barnase-d(CGAC) structure (Buckle \& Fersht, 1994) and are confined to the active site and flexible loop regions that have changed their crystal packing environment (Figure 8). The largest differences are found at the guanine binding loop (57-60), the loop segment 101-105, and at the base of the active site (Arg83, Arg87, Lys27, and Glu73). The differences here are larger than those observed in the barnase-d(CGAC) complex. An important movement is the side-chain rotation of the barnase active-site His 102 , whose $\chi_{2}$ torsion angle changes by $61^{\circ}$, enabling it to enter the preformed pocket on the barstar surface and hydrogen-bond to both Asp39 and Gly31 of barstar (Figures 6 and 8). This particular interaction has important implications for the $\mathrm{pH}$ dependency of barnase-barstar binding (see below).

Comparison of Free with Uncomplexed Wild-Type Barstar Reveals Significant Structural Differences. The structure of the barstar Cys $\rightarrow$ Ala double mutant in the complex with barnase was compared to the NMR solution structure of the reduced form of free, wild-type barstar. An initial comparison

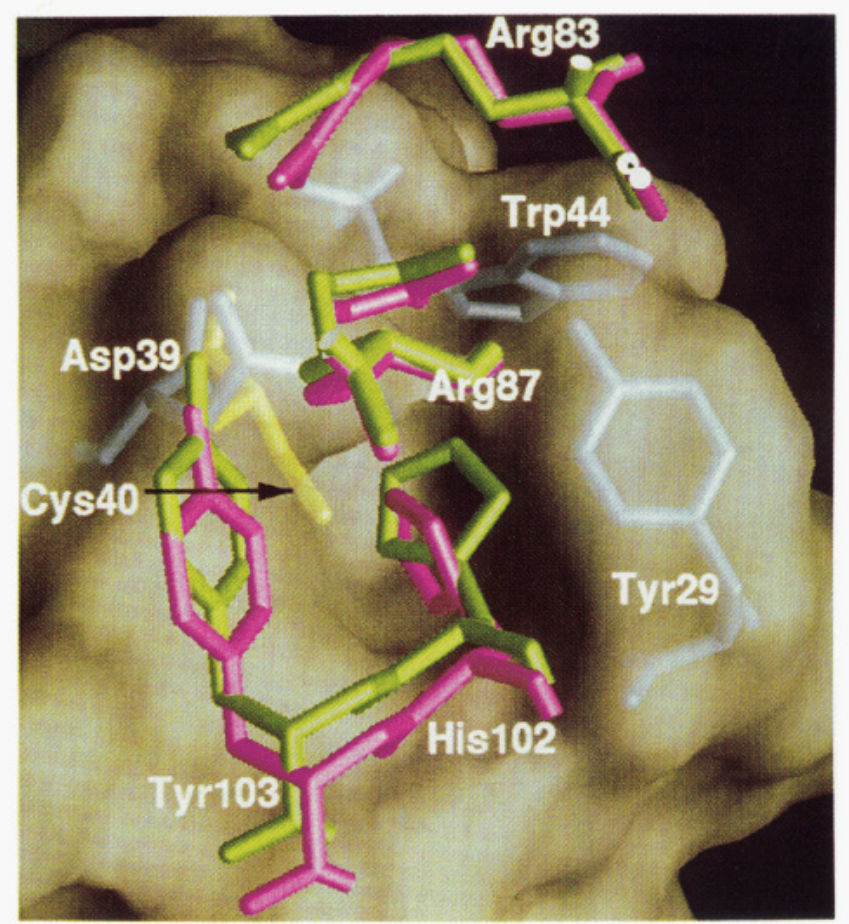

FIGURE 8: Interactions at the barnase-barstar interface, showing the pocket on the barstar surface that is occupied by the His 102 side chain of barnase. Some active-site residues of the superimposed, free barnase structure (green bonds) are shown for comparison. The surface of barstar is semitransparent, allowing some barstar residues that are important in barnase binding to be seen. The side chain of Cys40 in the NMR structure of reduced, free barstar (after a least-squares superposition with complexed barstar using $\mathrm{C} \alpha$ atoms in $\alpha$-helix ${ }_{2}$ ) is drawn in yellow. Residues are labeled. The surface was calculated and drawn with GRASP (Nicholls, 1992).

by a least-squares fit of both structures using all residues reveals differences that are distributed over the entire molecule (rms $=0.9 \AA$, based on a fit of all $\mathrm{C} \alpha$ atoms). Further leastsquares fitting using just $\beta$-sheet residues shows that, whereas the $\beta$-sheet residues are essentially superimposable (rms deviation of $\mathrm{C} \alpha$ positions is $0.55 \AA$ ), the remaining helical and loop regions show significant movements (Figure 9). These differences are best described as rigid-body, outward movements of the four helices, resulting in the free barstar structure being significantly more compact (the difference in molecular volumes was calculated to be $502 \AA^{3}$ ). It is unlikely that the expansion is due to the removal of two-SH groups; therefore, the majority of the conformational differences can be attributed to barnase binding. It is possible that the more expanded structure of complexed barstar, resulting in loosening of the hydrophobic core packing, is a consequence of the improved interaction between barnase and the more exposed surface of barstar $\alpha$-helix 2 (the expansion results in an increase of $43 \AA^{2}$

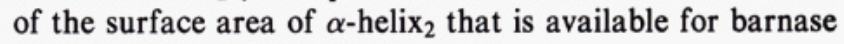
binding).

How does the structure of the barnase-binding site of barstar respond to barnase binding? A least-squares fit between free and complexed barstar using the $\mathrm{C} \alpha$ atoms of the residues in $\alpha$-helix $2(33-44)$ shows that the structural response to binding is restricted mainly to side-chain rotations in $\alpha$-helix h $_{2}$ and shifts in the adjoining loop (Figure 10). The most notable movement in $\alpha$-helix 2 is the side-chain rotation of Asp39 ( $\chi_{1}$ changes from $-173^{\circ}$ to $-98^{\circ}$ ) that is essential for optimal hydrogen-bonding with Arg83, Arg87, and His102 of barnase. The connecting loop region (29-33) also moves to maximize the close fit with barnase, especially the side chain of Tyr29, which makes two hydrogen bonds to barnase as well as packing 

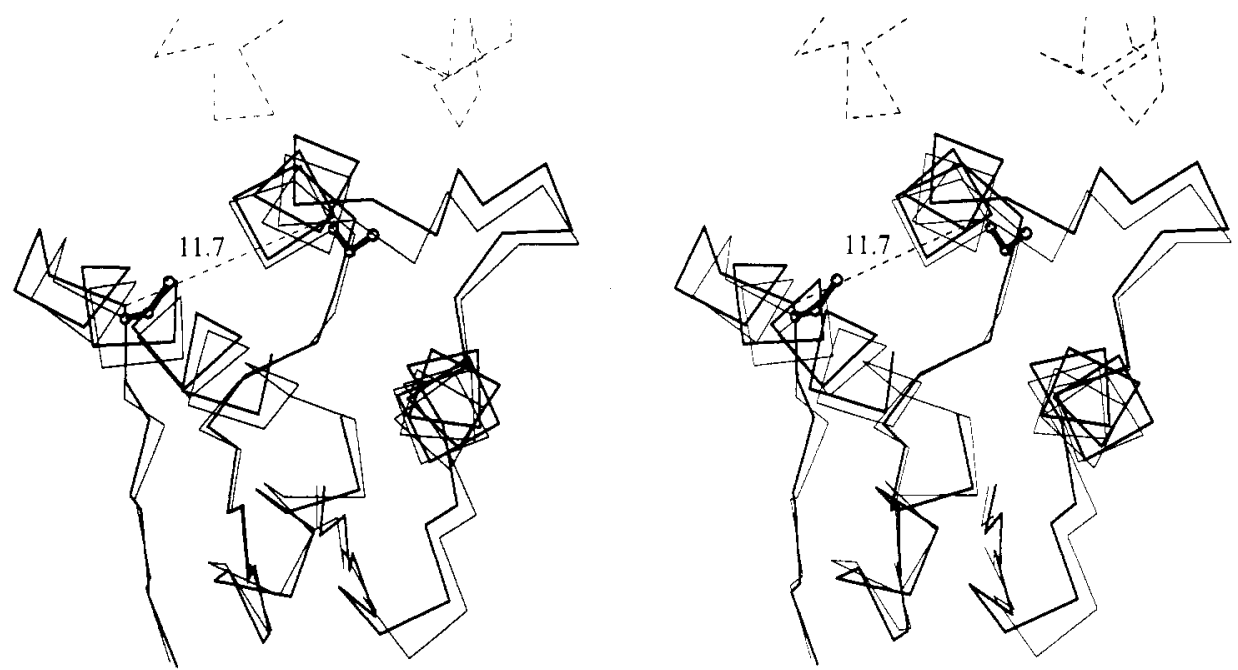

FIGURE 9: Stereoview showing a comparison between the NMR solution structure of the reduced form of wild-type barstar (thin bonds) and barstar chain D in the barnase-barstar complex (thick bonds). Both chains are represented by a C $\alpha$ trace. The two structures were superimposed by a least-squares fit using $C \alpha$ atoms of $\beta$-sheet residues. The figure shows the resultant rigid body movements of all four $\alpha$-helices. The distance $(A)$ between the $C \beta$ atoms of the mutated residues ( 40 and 82$)$ is shown as a broken line. Portions of the interacting barnase molecule are drawn as a broken $\mathrm{C} \alpha$ trace [drawn with MolScript (Kraulis, 1991)].
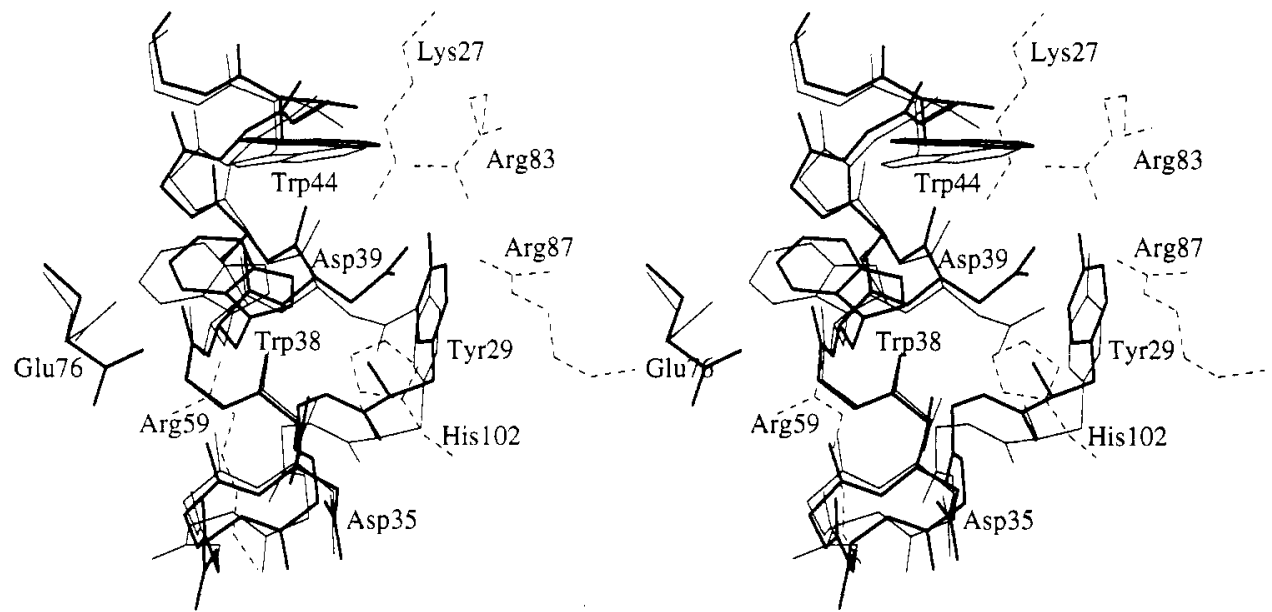

FIGURE 10: Stereoview showing the comparison between the NMR solution structure of the reduced form of wild-type barstar (thin bonds) and barstar chain $D$ in the barnase-barstar complex (thick bonds), showing residues in the barnase-binding region. Molecules were superimposed by a least-squares fit of residues in barstar $\alpha$-helix ${ }_{2}(33-44)$. Some of the interacting barnase residues are shown as broken bonds [drawn with MolScript (Kraulis, 1991)].

closely onto the side chain of barnase His 102 . The side chain of Glu76, which is not well defined in the free structure, becomes fixed upon barnase binding, so that it can accept two hydrogen bonds from the side chain of barnase Arg59. The -SH group of Cys 40 is located at the base of the pocket on the binding surface of barstar into which barnase His 102 side chain is inserted (Figure 8 ). It is possible that the removal of the close interaction between $\mathrm{Cys} 40-\mathrm{SH}$ and His 102 (SH...CE2 distance $=3.7 \AA$ ) in the Cys $\rightarrow$ Ala double mutant structure contributes to the weakening of the mutant barstarbarnase interaction. The structure comparison is valid due to the NMR structure being of high resolution. However, a more detailed analysis must await the high-resolution structural determination of the barstar Cys $\rightarrow$ Ala double mutant (work in progress).

Mobility of Residues at the Interface. Interface residues are more ordered in all three complexes in the asymmetric unit than the remaining structure (Table 3 ). This difference is larger in the case of barstar than in barnase, for two reasons. First, the barstar structure has, except for the CF complex, higher overall $B$ values than barnase residues. The high overall $B$ value for the barnase $C$ chain has been attributed to a lack of stabilizing crystal packing. Second, barstar interface residues are marginally more ordered than barnase interface residues. This is true for all complexes but is more noticeable for the CF complex.

The base of the active site is already relatively well ordered in the free barnase structure, and complexation does not result in a substantial decrease in mobility. This is not true, however, for the guanine binding loop (56-62) and residues 35-45. These regions of the structure are very mobile in the free structure but become ordered dramatically upon binding either barstar or the tetranucleotide d(CGAC) (Buckle \& Fersht, 1994). The mobility of interface residues and solvent is much higher in the $C F$ complex than the $\mathrm{AD}$ and $\mathrm{BE}$ complexes (Tables 3 and 4). This is largely a result of the high mobility of residues in the barnase $C$ chain, since there is little difference between $B$ values of interface residues and the remaining structure in the barstar $F$ chain. For this reason it can be argued that, in terms of mobility, the CF complex is more representative of a structure of a barnase-barstar complex in solution. From a comparison between $B$ values for the three barstar chains DEF and rms values of the energy-minimized, average NMR structure of free barstar, it can be seen that 
the general pattern of mobility of the free barstar structure resembles most that of the barstar chain $F$ in the barnasebarstar structure (Figure 3).

There are notable structural differences between the three molecules of barstar in the asymmetric unit of the barnasebarstar complex crystal (Guillet et al., 1993b). Superimposing the three barstar chains using the transformations from a least-squares fit of the three barnase chains reveals that, whereas the relative orientation of barstar $\alpha$-helix ${ }_{2}$ is invariable, there is some flexibility at each end of this helix that results in small, rigid-body movements of the remaining barstar structure.

\section{DISCUSSION}

Comparison with Other Protein-Protein Recognition Sites. Intermolecular hydrogen bonding plays a more important role in barnase-barstar recognition than in protease-inhibitor and antibody-antigen complexes, which involve an average of 10 intermolecular hydrogen bonds [standard deviation $=1.6$ (Janin \& Chothia, 1990)]. Almost half of the hydrogen bonds between barnase and barstar involve two charged residues, and a third involve one charged partner. These values are considerably greater than for other protein-protein interactions (Janin \& Chothia, 1990). Consequently, the hydrophobic contribution to binding is somewhat less for the barnasebarstar interaction. The strong electrostatic nature of the interaction is to be expected for the inhibition of an enzyme whose function is to cleave RNA by strongly binding its negatively charged phosphate groups.

The surface area buried in the barnase-barstar interface is of similar magnitude to other protein-protein complexes (Janin \& Chothia, 1990). There is a high degree of complementarity both in the shape and of the charge of the interacting surfaces, but neither is perfect. The surface complementarity is, on average, slightly less than in proteaseinhibitor complexes but a little better than in antibody-antigen interactions. However, the burial of solvent in the barnasebarstar interface improves the fit significantly by filling in the majority of gaps and seems to play a more important role than in other interactions. This is most likely a consequence of the relatively strong polar nature of the interface-it is expected that solvent can play little part in increasing the fit in more nonpolar interfaces. Since the majority of structural information on antibody-antigen interactions comes from mediumto-low-resolution studies (2.5-3.0 $\AA$ ), the importance of solvent in antigen recognition could well have been overlooked. More recent analysis of the 1.8-Å structure of a free and lysozymebound $F_{v}$ fragment has identified significantly more solvent at the protein-protein interface (Mariuzza \& Poljak, 1993). The role of the solvent in this case seems to be identical to that in the barnase-barstar interaction: that of bridging hydrogen bonds, particularly between charged partners, and filling in interfacial voids. Solvent-mediated hydrogen bonding is probably a general feature of macromolecular interactions, but in some cases its role might be more distinct, such as its putative contribution to specificity in the trp repressor/operator complex (Otwinowski et al., 1988).

Contributions of Different Interactions to Barnase-Barstar Binding. As discussed above, the dominant forces in barnasebarstar binding are electrostatic in nature. Although there are estimates of the free energies of hydrogen bonds and salt bridges obtained from protein engineering studies (Fersht et al., 1985; Serrano et al., 1992), their highly context-dependent nature means that they do not generally apply to all systems. However, we can see from the structure that barstar Asp39 and barnase Arg83, His 102, and Arg87 are expected to contribute the most to the overall binding energy in view of their many buried intermolecular hydrogen bonds. The magnitude of the interaction energies between two residues can be determined by double-mutant cycle analysis (Carter et al., 1984). This approach has been very successful in studying many interactions within barnase (Serrano et al., $1990,1991)$ and is currently being applied to the barnasebarstar complex. For these reasons, the barnase-barstar system is also well suited for rigorous theoretical calculations.

Roughly half of the buried solvent at the barnase-barstar interface is seen in the structure of free barnase. Judging by the equally charged nature of the interacting barstar surface, it is not unreasonable to assume that the majority of the remaining half of the interfacial solvent is present in the uncomplexed barstar structure. Additionally, most, if not all of the water forming the rim of the interface is recruited from bulk solvent. On the basis of this evidence, we suggest that complex formation is not driven by the favorable entropy increase from the release of bound solvent from the interface (the hydrophobic effect) but probably by an enthalpic contribution from protein-protein interactions and the large network of solvent-mediated hydrogen bonding in the core and at the rim of the interface. We do not expect this to be a general rule for all protein association reactions since the chemical character of the interface will vary among interactions. However, this has been shown to be true in the case of the $F_{v} D 1.3-$ lysozyme complex and is consistent with results from titration calorimetry studies (Mariuzza \& Poljak, 1993).

There will be an unfavorable entropy decrease on binding due to the loss of translational and rotational degrees of freedom of barnase and barstar. However, entropy losses due to the immobilization of segments of the protein chain and the energetic costs of conformational changes are both minimized due to the essentially preformed active site of barnase. The small movements of barnase residues at the interface do not represent large energetic penalties and serve to optimize the geometry of intermolecular interactions. The structural response to complexation is larger, however, in the case of barstar.

Relationship of Crystal Structure to Kinetics of BarnaseBarstar Binding. How does the crystal structure relate to the results of previous kinetic studies of the interaction (Hartley, 1993; Schreiber \& Fersht, 1993a)? The rate constants for barnase-barstar association and dissociation at $\mathrm{pH} 8$ are 6.0 $\times 10^{8} \mathrm{~s}^{-1} \mathrm{M}^{-1}\left(k_{\text {on }}\right)$ and $8.0 \times 10^{-6} \mathrm{~s}^{-1}\left(k_{\mathrm{off}}\right)$, respectively (Schreiber \& Fersht, 1993a). The dissociation constant, calculated from the ratio $k_{\text {off }} / k_{\text {on }}$, is $1.3 \times 10^{-14} \mathrm{M}$, which corresponds to a $\Delta G$ of $-18.9 \mathrm{kcal} \mathrm{mol}^{-1}$ at $25^{\circ} \mathrm{C}$. The association rate is extremely fast, being around 100 times faster than protease-inhibitor and antibody-antigen associations (Nobel et al., 1969; Ward et al., 1989). The much slower rate constant of $10^{6} \mathrm{~s}^{-1} \mathrm{M}^{-1}$ for the latter interactions has been predicted by Brownian dynamics simulations for associations governed by simple diffusive processes and not involving any steering forces (Northrup \& Erickson, 1992). By virtue of the highly charged nature of the barnase-barstar interface and the dependence of association on ionic strength (Schreiber \& Fersht, 1993), we expect that the faster rate constant results from electrostatic steering effects.

Schreiber and Fersht (1993a) found three barnase mutants that have even higher association rate constants with barstar, Asp $\rightarrow$ Ala54, Glu $\rightarrow$ Ala73, and Glu $\rightarrow$ Ala60. In these cases, $k_{\text {on }}$ increases to $(1.8-4.5) \times 10^{9} \mathrm{~s}^{-1} \mathrm{M}^{-1}$ and is approaching the theoretical diffusion-controlled rate of $7.0 \times 10^{9} \mathrm{~s}^{-1} \mathrm{M}^{-1}$ 
(Fersht, 1985). Close inspection of the sites of mutation in the structure of the complex reveals that each mutation relieves, to varying degrees, unfavorable interactions between acidic groups of barnase and barstar. Since the fast association rates are a direct consequence of the strong electrostatic attraction between the oppositely charged surfaces of barnase and barstar, it is not surprising that the deletion of acidic groups in the barnase active site results in faster association rate constants (see Figure 5, top). Each mutation is discussed in more detail below. First, Asp54 does not directly hydrogen-bond with barstar but is found in the vicinity of the barstar Glu80 residue (side chain $\mathrm{O} \ldots \mathrm{O}$ distance $\sim 7 \AA$ ). Mutation of this residue to Ala removes the hydrogen bond between Asp54 and barnase Lys 27 and its $\mathrm{N}$-cap and dipole interaction with barnase $\alpha$-helix ${ }_{2}$, but these losses are outweighed by the energetic gain from the removal of the unfavorable Asp54-Glu80 interaction. It has been observed that an Asp $\rightarrow$ Asn 54 mutation increases the catalytic efficiency of barnase toward an RNA substrate (Meiering et al., 1992). This could equally be explained by the removal of an unfavorable Asp54-phosphate interaction, on the basis of the barnase-d(CGAC) structure (Buckle \& Fersht, 1994). The barnase Glu $\rightarrow$ Ala 73 mutation removes an unfavorable interaction with barstar Asp39 (side chain O...O distance $\sim 4.5 \AA$ ), resulting in a 4 -fold increase in $k_{\text {on }}$. The resulting complex is less stable, however, by some 1.8 $\mathrm{kcal} \mathrm{mol}^{-1}$. This is most likely due to the removal of hydrogenbonding interactions with barnase active-site residues. Finally, the barnase mutant Glu $\rightarrow$ Ala60 results in the largest (7.5fold) increase in $k_{\text {on }}$. This mutation removes the unfavorable interaction with Asp35 (side chain O...O distance $\sim 6 \AA$ ) as well as the stabilizing interactions with the macrodipole and $\mathrm{N}$-cap of barstar $\alpha$-helix 2 . The stability of the complex, however, is unchanged. For these three mutations there is a relationship between $k_{\text {on }}$ and the number of solvent molecules that are found in the spaces separating the acidic residues. That is, where possible, solvent can lower the unfavorable charge-charge repulsion, resulting in smaller $k_{\text {on }}$ increases upon removing one of the charges. The unfavorable electrostatic interactions and their degree of solvation can be clearly seen in Figures 5 and 7.

The removal of a negative charge on the barnase-binding surface of barstar has a considerably smaller effect on the overall association rate than the removal of a charged residue in the active site of barnase (G. Schreiber, unpublished results). One explanation for this is that the removal of a charged residue in the barnase active site will affect the balance between the four positive and three negative charges, making it either more or less attracted to barstar. On the other hand, the barnase-binding site on barstar is exclusively negatively charged, so the deletion of one of these charges merely weakens the overall negative charge.

The $\mathrm{pH}$ dependence for dissociation of the complex has been attributed unequivocally to the barnase His 102 residue (Schreiber \& Fersht, 1993a). This can be explained quite simply by its hydrogen bond to Gly $31>\mathrm{NH}$ of barstar (Figures 6 and 8 ), which can occur only when the imidazole group is unprotonated. The conformational changes that would be required in order to relieve the steric clashes that result from protonation could not possibly be accommodated by the interface structure. The $\mathrm{p} K_{\mathrm{a}}$ of His 102 is subsequently lowered from 6.3 in wild-type barnase (Sali et al., 1988) to less than 5.0 in the barnase-barstar complex (Schreiber \& Fersht, 1993a).

The relative stabilities of His 102 mutants investigated by Hartley (1993) can be rationalized on a structural basis to some extent. Mutation to Ala was found to destabilize the complex by $6.9 \mathrm{kcal} \mathrm{mol}^{-1}$, whereas mutation to Asp or Gln resulted in a smaller destabilization of $4.5 \mathrm{kcal} \mathrm{mol}^{-1}$. While the $\mathrm{His} \rightarrow$ Ala 102 mutant removes two good hydrogen bonds with barstar, it is possible to model an Asp residue at position 102 in a statistically preferred side-chain conformation (Ponder \& Richards, 1987) so that the hydrogen bond with barstar Gly31 >NH can be retained, without introducing any steric clashes. A large proportion of the residual destabilization probably results from the unfavorable electrostatic interaction between Asp102 and barstar Asp39. The His $\rightarrow \mathrm{Gln} 102$ mutation can be modeled in a similar way, although the Gin side chain is too lengthy to fit into the pocket on the surface of barstar. We would expect, therefore, a large degree of structural reorganization.

There is evidence to suggest that barnase-barstar binding involves two steps (Schreiber \& Fersht, 1993a). The first, diffusion-controlled step results in the formation of an "encounter" complex, which then slowly rearranges to the fully formed complex. The barnase mutations Arg $\rightarrow$ Ala 59, Lys $\rightarrow$ Ala 27, Arg $\rightarrow$ Ala 87, and His $\rightarrow$ Ala 102 all destabilize the complex by similar amounts $\left(5.2-6.3 \mathrm{kcal} \mathrm{mol}^{-1}\right)$ yet have different effects on the association and dissociation kinetics. Of the nine barnase mutants studied by Schreiber and Fersht (1993a), Arg $\rightarrow$ Ala59 and Lys $\rightarrow$ Ala27 cause the largest decrease in association rates. These two flexible basic residues could be of great importance in contributing to an electrostatic steering effect and making initial encounters with the barstar molecule. Conversely, the mutations Arg $\rightarrow$ Ala87 and $\mathrm{His} \rightarrow \mathrm{Ala} 102$ cause the largest increases in dissociation rates. Both residues are at the base of the barnase active site depression, and their interactions are probably not important until after the formation of the initial encounter complex.

Relationship between the Barnase-Barstar Complex and Barnase-RNA Interactions. Barnase has evolved to bind both RNA and barstar, since each function is of importance to the survival of the organism. The structure of barnase represents, therefore, a compromise between these two roles. For example, we have already discussed the barnase mutations that lead to faster association rates with barstar, but these would also render the enzyme inactive toward RNA. The clustering of positively charged residues in the active site of barnase that is fundamental to its interaction with both RNA and barstar has been shown even to destabilize its folded structure and represents the compromise between structural stability and activity (Meiering et al., 1992). Preliminary measurements of the free energy of folding of the barstar mutants Asp $\rightarrow$ Ala39, Asp $\rightarrow$ Ala35, Glu $\rightarrow$ Ala 76, and Glu $\rightarrow$ Ala80 indicate that these residues also destabilize the barstar structure to some extent (G. Schreiber, unpublished results). Although previous structural studies of the barnase-ribonucleotide interaction have accounted for the functional importance of most of the active-site residues, the significance of the solvent-exposed Phe82 side chain that protrudes from the edge of the active site has remained unclear. It has been suggested that this residue could be involved in subsite interactions with an RNA substrate (Guillet et al., 1993a). However, since this residue is located at the edge of the barnase-barstar interface, burying some $28 \AA^{2}$ of accessible surface area via its interaction with the side chain of barstar Trp44, it is more likely that its function is more related to barstar binding than to RNA binding.

It is not absolutely necessary that barstar inhibits barnase by imitating its interaction with RNA, just that it sterically blocks the active site by forming a tight $1: 1$ complex. In this 
way, there is no requirement to mimic a guanine in the barnase recognition site. Although it is energetically favorable for both binding sites to be essentially preformed in the free structures, a certain degree of flexibility within the barnase active site is required to allow for the differences between barnase-barstar binding and barnase-RNA binding. This is exemplified by the mobility of the barnase guanine binding loop (57-60) and in the region 35-45.

Functional Implications of the Cys40-Cys82 Barstar Disulfide Bond. Both oxidized and reduced species of barstar inhibit barnase, the latter binding being slightly weaker (Hartley, 1993; G. Schreiber, unpublished results). The structure of the barnase-barstar complex shows that large conformational shifts would be necessary in order for a disulfide bond to form (Figure 9). In particular, barstar $\alpha$-helix ${ }_{2}$ would have to rotate around its axis significantly, resulting in some disruption of the hydrophobic core packing and the residues in the barnase binding site. The flexibility around $\alpha$-helix 2 exhibited by the three barstar molecules in the asymmetric unit of the barnase-barstar crystal structure supports this argument. It is interesting that preliminary modeling of this conformational movement indicates that the helix rotation could result in the occupation of the barnase guanine recognition site by the side chain of barstar Trp38 (unpublished results).

\section{ACKNOWLEDGMENT}

We are grateful to Dr. Michael Lawrence for his generous gift of the program SHAPE.

\section{REFERENCES}

Baudet, S., \& Janin, J. (1991) J. Mol. Biol. 219, 123-132.

Brunger, A. T. (1992) XPLOR Manual, Version 3.0., Yale University, New Haven, CT.

Buckle, A. M., \& Fersht, A. R. (1994) Biochemistry 33, 1644 1653.

Buckle, A. M., Henrick, K., \& Fersht, A. R. (1993) J. Mol. Biol. 234, 847-860.

Carter, P. J., Winter, G., Wilkinson, A. J., \& Fersht, A. R. (1984) Cell 38, 835-840.

Castellano, E. E., Oliva, G., \& Navaza, J. (1992) J. Appl. Crystallogr. 25, 281-284.

CCP4 (1979) The SERC (U.K.) Collaborative Computing Project No. 4, A Suite of Programs for Protein Crystallography, distributed from Daresbury Laboratory, Warrington WA4 4AD, U.K.

Chen, Y. W., Fersht, A. R., \& Henrick, K. (1993) J. Mol. Biol. 234, 1158-1170.

Connolly, M. L. (1983) J. Appl. Crystallogr. 16, 548-558.

Fersht, A. R. (1985) Enzyme Structure and Mechanism, W. H. Freeman and Company, New York.

Fersht, A. R. (1993) FEBS Lett. 325, 5-16.

Fersht, A. R., et al. (1985) Nature (London) 314, 235-238.

Flocco, M. M., \& Mowbray, S. L. (1994) J. Mol. Biol. 235, 709-717.

Guillet, V., Lapthorn, A., \& Mauguen, Y. (1993a) FEBS Lett. $330,137-140$
Guillet, V., Lapthorn, A., Hartley, R. W., \& Mauguen, Y. (1993b) Structure 1, 165-176.

Hartley, R. W. (1993) Biochemistry 32, 5978-5984.

Janin, J., \& Chothia, C. (1990) J. Biol. Chem. 265, 1602716030.

Jones, T. A., Zou, J.-Y., Cowan, S. W., \& Kjeldgaard, M. (1991) Acta. Crystallogr. A47, 110-119.

Kraulis, P. (1991) J. Appl. Crystallogr. 24, 946-950.

Lawrence, M. L., \& Colman, P. M. (1993) J. Mol. Biol. 234, 946-950.

Leslie, A. G. W. (1990) in Crystallographic Computing, Oxford University Press, Oxford, U.K.

Lubienski, M. J., Bycroft, M., Jones, D. N. M., \& Fersht, A. R. (1993) FEBS Lett. 332, 81-87.

Lubienski, M. J., Bycroft, M., Freund, S. M. V., \& Fersht, A. R. (1994) Biochemistry (following paper in this issue).

Mariuzza, R. A., \& Poljak, R. J. (1993) Curr. Opin. Immunol. $5,50-55$.

Mauguen, Y., Hartley, R. W., Dodson, E. J., Dodson, G. G., Bricogne, G., Chothia, C., \& Jack, A. (1982) Nature 29, 162164.

McPherson, A. (1982) The Preparation and Analysis of Protein Crystals, John Wiley \& Sons, New York.

Meiering, E. M., Serrano, L., \& Fersht, A. R. (1992) J. Mol. Biol. 225, 585-589.

Morris, A. L., Macarthur, M. W., Hutchinson, E. G., \& Thornton, J. M. (1992) Proteins 12, 345-364.

Navaza, J. (1987) Acta. Crystallogr. A43, 645-650.

Navaza, J. (1994) Acta. Crystallogr. (in press).

Nicholls, A. (1992) GRASP, Graphical Representation and Analysis of Surface Properties, Columbia University, New York.

Nicholson, H., Becktel, W. J., \& Matthews, B. W. (1988) Nature (London) 336, 651-656.

Nobel, R. W., Reichlin, M., \& Gibson, Q. H. (1969) J. Biol. Chem. 244, 2403-2411.

Northrup, S. H., \& Erickson, H. P. (1992) Proc. Natl. Acad.Sci. U.S.A. 89, 3338-3342.

Otwinowski, Z., Schevitz, R. W., Zhang, R. G., Lawson, C. L., Joachimiak, A., Marmorstein, R. Q., Luisi, B. F., \& Sigler, P. B. (1988) Nature (London) 335, 321-329.

Ponder, J. W., \& Richards, F. M. (1987) J. Mol. Biol. 193, 775-791.

Richardson, J.S., \& Richardson, D. C. (1988) Science 240, 16481652.

Sali, D., Bycroft, M., \& Fersht, A. R. (1988) Nature (London) $335,496-500$.

Schreiber, G., \& Fersht, A. R. (1993a) Biochemistry 32, 51455150.

Schreiber, G., \& Fersht, A. R. (1993b) Biochemistry 32, 11195 11203.

Serrano, L., \& Fersht, A. R. (1989) Nature (London) 342, 296299.

Serrano, L., Horovitz, A., Avron, B., Bycroft, M., \& Fersht, A. R. (1990) Biochemistry 29, 9343-9352.

Serrano, L., Bycroft, M., \& Fersht, A. R. (1991) J. Mol. Biol. $218,465-475$.

Serrano, L., Kellis, J. T., Jr., Cann, P., Matouschek, A., \& Fersht, A. R. (1992) J. Mol. Biol. 224, 783-804.

Ward, E. S., Gussow, D., Griffiths, A. D., Jones, P. T., \& Winter, G. (1989) Nature (London) 341, 544-546.

Wilson, A. J. C. (1949) Acta Crystallogr. 2, 318. 